\title{
AVALIAÇÃO DA EFICIÊNCIA DE COMBATE AOS INCÊNDIOS FLORESTAIS EM UNIDADES DE CONSERVAÇÃO BRASILEIRAS
}

\author{
Gumercindo Souza Lima ${ }^{1 *}$, Fillipe Tamiozzo Pereira Torres ${ }^{1}$, Aline das Graças Costa ${ }^{2}$, Gleidson de Araújo \\ Félix $^{3}$, Milton Ribas da Silva Júnior ${ }^{3}$ \\ ${ }^{1}$ Universidade Federal de Viçosa, Professor do Departamento de Engenharia Florestal, Viçosa, Minas Gerais, Brasil - gslima@ufv.br*, \\ fillipe.torres@ufv.br \\ ${ }^{2}$ Universidade Federal de Viçosa, Mestranda do Programa de Pós-Graduação em Ciência Florestal, Viçosa, Minas Gerais, Brasil - \\ alinegrcosta@gmail.com \\ ${ }^{3}$ Universidade Federal de Viçosa, Acadêmico do Curso de Engenharia Florestal, Viçosa, Minas Gerais, Brasil - gleidsonfelix88@ gmail.com, \\ miltonribas1@gmail.com
}

Recebido para publicação: 28/06/2017 - Aceito para publicação: 01/12/2017

\begin{abstract}
Resumo
O objetivo deste trabalho foi avaliar a eficiência de combate aos incêndios florestais em unidades de conservação brasileiras no período de 2008 a 2012. Foram utilizados três parâmetros principais para se avaliar a eficiência de combate: a área queimada, em que se avaliou a eficiência, distribuindo os incêndios ocorridos por classes de tamanho, e se observou a área queimada média por incêndio; o tempo para o ataque e sua distribuição por classe de tempo, em que se avaliou a eficiência de mobilização dos combatentes em termos de média de tempo desde a detecção até o primeiro ataque por incêndio; e o tempo de combate, em que se avaliou o tempo médio de combate e sua distribuição por classe de tempo de combate. No período analisado, o Brasil apresentou uma baixa eficiência de combate. A área queimada média em unidades de conservação brasileiras, neste período, foi de 613,61 ha. O tempo médio para ataque e o tempo médio de combate foram, respectivamente, de 194,82 e 1.012,51 minutos. A principal dificuldade no estudo foi a falta de preenchimento completo dos Registros de Ocorrências de Incêndios (ROI).
\end{abstract}

Palavras-chave: Fogo, Brasil, unidades de conservação, Registros de Ocorrências de Incêndios.

\begin{abstract}
Assessment of firefighting efficiency in Brazilian conservation units. The objective of this study was to assess the firefighting efficiency in Brazilian conservation units from 2008 to 2012. Three main parameters were used to evaluate the combat efficiency: burned area, in which efficiency was evaluated, the fires were distributed by size classes, and the average burned area by fire was observed; time for attack and its distribution by time class, in which the firefighters mobilization efficiency was evaluated in terms of average time from detection until the first fire attack; and time of combat, in which the average time of combat and its distribution by class of time of combat were evaluated. In the analysed period, Brazil presented a low combat efficiency. The average burned area in Brazilian protected areas was 613.61 ha in this period. The average time for attack and the average time of combat were 194.82 and 1,012.51 minutes, respectively. The main difficulty in the study was the lack of complete data of the Record of Fire Occurrence (ROI).

Keywords: Fire, Brazil, conservation units, ROI.
\end{abstract}

\section{INTRODUÇÃO}

Incêndios resultam em mudanças drásticas em todos os tipos de ecossistemas florestais (ZAITSEV et al., 2016). Eles têm forte impacto tanto sobre as condições bióticas como as abióticas (ADÁMEK et al., 2015). Nas Unidades de Conservação (UC), áreas ambientais destinadas primordialmente a proteção, os incêndios florestais são uma grave perturbação, que pode colocar em risco os processos ambientais e a biodiversidade. Na grande maioria das UCs brasileiras, não existe um planejamento adequado visando à prevenção e ao combate a incêndios (BONTEMPO et al., 2011).

Grande parte dessa dificuldade no planejamento está relacionada a fatores incertos e altamente variáveis, tais como condições meteorológicas, ação antrópica, comportamento do fogo e propagação e seus efeitos. Estes são a base da gestão de incêndios e decisões políticas, através de múltiplos níveis e escalas, e são responsáveis pela eficiência dos recursos destinados ao combate e supressão (PACHECO et al., 2015). Em contrapartida, com uma quantidade limitada de equipamentos e recursos financeiros e humanos, os gestores florestais devem decidir a aplicação mais eficiente de subsídios em ações, como prevenção (ex. campanhas de educação ambiental), gestão de combustível (ex. queima prescrita e tratamentos mecânicos), pré-supressão (ex. planejamento e preparação,

FLORESTA, Curitiba, PR, v. 48, n. 1, p. 113-122, jan./mar. 2018.

Lima. G. S. et al.

ISSN eletrônico 1982-4688

DOI: $10.5380 /$ rf.v48 i1.53550 
recrutamento e treinamento de bombeiros, manutenção de aceiros e pontos de água), supressão e medidas de restauração (MAVSAR et al., 2010).

Assim, o conhecimento do perfil dos incêndios florestais nas UCs e da logística associada ao seu combate é fundamental para se traçarem estratégias eficientes para o planejamento de ações de prevenção e combate. A eficiência no combate aos incêndios florestais, de acordo com Bonazountas et al. (2007), pode ser conceitualmente simplificada como a minimização do tempo envolvido nas operações, tais como detecção dos incêndios, comunicação com a base, preparação e início das operações, deslocamento, implantação de recursos na área da ocorrência, controle e extinção do fogo. Também, envolve o conhecimento do pessoal de combate e equipamentos disponíveis para cada tipo de combustível em circunstâncias que são, em grande parte, variáveis.

$\mathrm{Na}$ Europa, a maioria dos incêndios são pequenos graças às políticas com esforços voltados para a supressão que prevalece no continente. Assim, os incêndios são extintos o mais rápido possível e apenas uma pequena porcentagem escapa do ataque inicial e das operações de combate a incêndios subsequentes (SANMIGUEL-AYANZ et al., 2013). Em outro estudo europeu, nos países alpinos, Wastl et al. (2013) mostram que grandes incêndios individuais ocorreram principalmente onde as operações de combate são mais difíceis.

Ano após ano, o Brasil vem sofrendo grandes perdas nas áreas protegidas em decorrência do descontrole do fogo. No que diz respeito às normas ambientais do país, não existe uma política consolidada que trata da prevenção e do combate a incêndios florestais, o que leva a irremediáveis perdas naturais. Além disso, as estatísticas existentes acerca da eficiência de combate dos incêndios florestais ainda são pouco confiáveis, devido à inexistência de estudos que forneçam informações necessárias para análises mais eficientes (TETTO et al., 2012). Nesse sentido, diversos estudos vêm sendo realizados em UCs no Cerrado (e. g. PEREIRA et al., 2004; FIEDLER et al., 2006; MAGALHÃES et al., 2011), Amazônia (e. g. GOUVEIA; MORAIS, 2004) e Mata Atlântica (e. g. GOBBO et al., 2013; TEBALDI et al., 2013), embora nenhum tenha se proposto a fazer uma análise em todo território nacional.

Diante do exposto, o objetivo deste estudo foi analisar o combate aos incêndios florestais em unidades de conservação brasileiras a fim de se obterem informações que possam melhorar a eficiência tanto da alocação de recursos como das estratégias de combate utilizadas atualmente.

\section{MATERIAIS E MÉTODOS}

Neste estudo, foram analisados os dados referentes às unidades federais pertencentes ao Sistema Nacional de Unidades de Conservação (SNUC). No Brasil, existem, atualmente, 954 unidades federais, englobando $764.464 \mathrm{~km}^{2}$. Destes, 27,1\% localizam-se na Amazônia, 7,7\% na Caatinga, 8,5\% no Cerrado, $10 \%$ na Mata Atlântica, 2,7\% nos Pampas, e 4,6\% no Pantanal (MMA, 2016). Dentro do período de estudo, 4.711,54 $\mathrm{km}^{2}$ foram queimados em 55 unidades de acordo com as informações obtidas.

Os dados utilizados foram coletados a partir dos Registros de Ocorrências de Incêndios (ROI), do período de 2008 a 2012, por meio do banco de dados do Sistema Nacional de Informações sobre Fogo (SISFOGO) do Centro Nacional de Prevenção aos Incêndios Florestais (PREVFOGO), mantido pelo Instituto Brasileiro do Meio Ambiente e dos Recursos Naturais Renováveis (IBAMA, 2015), Foi realizada consulta pública de registros.

Por meio dos ROIs, as unidades de conservação podem manter um banco de dados adequado sobre os incêndios florestais que ocorreram, conhecer o perfil dos incêndios e traçar melhores estratégias de prevenção e combate. Os ROIs contêm informações sobre a localização do incêndio, dados geográficos do terreno, dados meteorológicos durante o evento, polígono da área queimada, dados de combate, origem, causa e danos.

Foram obtidos 1.838 ROIs nas unidades de conservação brasileiras para o período analisado. Os dados foram organizados e tabulados em programa de planilha específico, onde foi formado um arquivo base com as estatísticas de incêndios florestais em UCs no período de 2008 a 2012. Os ROIs que não continham todos os dados referentes aos parâmetros necessários para a avaliação da eficiência de combate foram descartados. A amostragem com dados completos utilizada neste estudo totalizou 768 registros. Os parâmetros utilizados foram: área queimada (AQ); tempo de mobilização ou tempo para o primeiro ataque (TA); número de combatentes (NC); e tempo de combate (TC).

Os dados coletados sobre os incêndios florestais foram separados em classes de acordo com o tamanho da área queimada. A classificação adotada foi a do Canadian Forest Service (SANTOS et al., 2006), que é usada internacionalmente e considera cinco classes de tamanho (Tabela 1). Por princípio, na análise dessa variável, foi considerado que um número maior de incêndios concentrados nas classes I e II indicam melhor eficiência de combate. 
Tabela 1. Classes de tamanho dos incêndios florestais em UCs brasileiras no período de 2008 a 2012.

Table 1. . $\quad$ Size classes of forest fires in Brazilian UCs from 2008 to 2012.

\begin{tabular}{ccc}
\hline Classe de tamanho & Área queimada (hectares) \\
\hline I & 0 a 0,09 \\
II & 0,1 a 4,0 \\
III & 4,1 a 40,0 \\
IV & 40,1 a 200,0 \\
V & Acima de 200,0 \\
\hline Fonte: Santos $e t$ al $(2006)$ &
\end{tabular}

Fonte: Santos et al. (2006)

O segundo parâmetro avaliado (tempo para o primeiro ataque) corresponde ao tempo que transcorre desde a detecção do incêndio até o primeiro ataque ao fogo. É separado em cinco classes de duração (Tabela 2), sendo que a maior eficiência de combate se dá quanto maior for o número de ocorrências dentro das primeiras classes.

Tabela 2. .Classes de duração de tempo (minutos) para o ataque a incêndios florestais em UCs brasileiras no período de 2008 a 2012.

Table 2. . Time duration classes (minutes) for forest fire attack in Brazilian UCs from 2008 to 2012.

\begin{tabular}{cc}
\hline Classe de duração & Tempo de ataque (minutos) \\
\hline I & 0 a 30 \\
II & 31 a 60 \\
III & 61 a 120 \\
IV & 121 a 480 \\
V & Acima de 480 \\
\hline
\end{tabular}

Fonte: Lima e Soares (1992)

Além desses parâmetros, os incêndios florestais também foram distribuídos em quatro classes segundo a duração do tempo de combate (Tabela 3). Dada a semelhança dos parâmetros de área queimada e tempo para ataque, considerou-se uma melhor eficiência de combate quando um número maior de incêndios se concentraram nas primeiras classes.

Tabela 3. Classes de duração de tempo (minutos) de combate a incêndios florestais em UCs brasileiras no período de 2008 a 2012.

Table 3. Time duration classes (minutes) of forest firefighting time in Brazilian UCs from 2008 to 2012.

\begin{tabular}{cc}
\hline Classe de duração & Tempo de ataque (minutos) \\
\hline I & 0 a 60 \\
II & 61 a 120 \\
III & 121 a 480 \\
IV & Acima de 480 \\
\hline
\end{tabular}

Fonte: Lima e Soares (1992)

Foi feita análise de variância para os dados de área queimada (AQ) e número de incêndios registrados. Foram considerados cada um dos cinco anos (de 2008 a 2012) como sendo um tratamento, e os resultados foram agrupados de acordo com sua similaridade estatística. Como o número de registros de incêndios no período de 2008 a 2012 foi diferente para cada estado, foi utilizado, para a análise da variância, o teste de agrupamento de médias de Scott-Knott a 5\% de probabilidade. Para saber se há uma correlação entre área queimada, tempo de ataque, tempo de combate e número de combatentes, foi criada uma matriz de correlação de Spearman. Todas as análises estatísticas foram realizadas em ambiente R.

\section{RESULTADOS}

Os registros analisados foram separados em 5 classes de tamanho, segundo o Canadian Forest Service (Tabela 4). Dos 768 registros de incêndios analisados, 4,3\% estão inseridos na classe de tamanho I ( 0 a 0,09 ha), enquanto que $44,9 \%$ se encontram na classe II ( 0,1 a 4,0 ha) e $30,5 \%$ na classe III ( 4,1 a 40,0 ha).

FLORESTA, Curitiba, PR, v. 48, n. 1, p. 113-122, jan./mar. 2018.

Lima. G. S. et al.

ISSN eletrônico 1982-4688

DOI: $10.5380 /$ rf.v48 i1.53550 
Tabela 4. Distribuição da ocorrência de incêndios florestais por classe de tamanho em UCs brasileiras no período de 2008 a 2012.

Table 4. Distribution of occurrence of forest fires by size class in Brazilian UCs from 2008 to 2012.

\begin{tabular}{|c|c|c|c|c|c|c|c|c|c|c|}
\hline \multirow{2}{*}{ Estados } & \multicolumn{2}{|c|}{ Classe I } & \multicolumn{2}{|c|}{ Classe II } & \multicolumn{2}{|c|}{ Classe III } & \multicolumn{2}{|c|}{ Classe IV } & \multicolumn{2}{|c|}{ Classe V } \\
\hline & N. & $\%$ & N. & $\%$ & N. & $\%$ & N. & $\%$ & N. & $\%$ \\
\hline$\overline{\mathrm{RR}}$ & - & - & 1 & 100,00 & - & - & - & - & - & - \\
\hline PA & - & - & - & - & 2 & 100,00 & - & - & - & - \\
\hline AP & - & - & 1 & 50,00 & - & - & 1 & 50,00 & - & - \\
\hline RO & - & - & 1 & 50,00 & - & - & - & - & 1 & 50,00 \\
\hline TO & - & - & - & - & 2 & 10,53 & - & - & 17 & 89,47 \\
\hline Região N & - & - & 3 & 11,54 & 4 & 15,38 & 1 & 3,85 & 18 & 69,23 \\
\hline$\overline{\mathrm{PE}}$ & - & - & 6 & 85,71 & 1 & 14,29 & - & - & - & - \\
\hline $\mathrm{AL}$ & - & - & 6 & 66,67 & 3 & 33,33 & - & - & - & - \\
\hline PB & 3 & 4,55 & 37 & 56,06 & 25 & 37,88 & 1 & 1,52 & - & - \\
\hline SE & - & - & - & - & 1 & 25,00 & 2 & 50,00 & 1 & 25,00 \\
\hline $\mathrm{CE}$ & 14 & 8,86 & 105 & 66,46 & 30 & 18,99 & 7 & 4,43 & 2 & 1,27 \\
\hline MA & - & - & - & - & - & - & 1 & 33,33 & 2 & 66,67 \\
\hline BA & 1 & 4,35 & 2 & 8,70 & 4 & 17,39 & 7 & 30,43 & 9 & 39,13 \\
\hline PI & - & - & 7 & 10,14 & 28 & 40,58 & 25 & 36,23 & 9 & 13,04 \\
\hline Região NE & 18 & 5,31 & 163 & 48,08 & 92 & 27,14 & 43 & 12,68 & 23 & 6,78 \\
\hline $\mathrm{RS}$ & 3 & 12,50 & 6 & 25,00 & 9 & 37,50 & 4 & 16,67 & 2 & 8,33 \\
\hline PR & - & - & 2 & 12,50 & 4 & 25,00 & 3 & 18,75 & 7 & 43,75 \\
\hline Região S & 3 & 7,50 & 8 & 20,00 & 13 & 32,50 & 7 & 17,50 & 9 & 22,50 \\
\hline $\mathrm{ES}$ & - & - & 1 & 50,00 & - & - & 1 & 50,00 & - & - \\
\hline RJ & 2 & 1,79 & 50 & 44,64 & 52 & 46,43 & 7 & 6,25 & 1 & 0,89 \\
\hline SP & 1 & 7,69 & 4 & 30,77 & 4 & 30,77 & 1 & 7,69 & 3 & 23,08 \\
\hline MG & 2 & 2,25 & 41 & 46,07 & 19 & 21,35 & 12 & 13,48 & 15 & 16,85 \\
\hline Região SE & 5 & 2,31 & 96 & 44,44 & 75 & 34,72 & 21 & 9,72 & 19 & 8,80 \\
\hline$\overline{\mathrm{DF}}$ & 4 & 5,41 & 46 & 62,16 & 22 & 29,73 & 2 & 2,70 & - & - \\
\hline MT & 3 & 4,35 & 29 & 42,03 & 28 & 40,58 & 5 & 7,25 & 4 & 5,80 \\
\hline GO & - & - & - & - & - & - & 1 & 25,00 & 3 & 75,00 \\
\hline Região CO & 7 & 4,76 & 75 & 51,02 & 50 & 34,01 & 8 & 5,44 & 7 & 4,76 \\
\hline Brasil & 33 & 4,30 & 345 & 44,92 & 234 & 30,47 & 80 & 10,42 & 76 & 9,90 \\
\hline
\end{tabular}

A distribuição do número de incêndios florestais, área queimada e média do tamanho da área queimada por ocorrência em UCs no período estudado pode ser observada na Tabela 5.

Tabela 5. Distribuição do número de incêndios florestais, área queimada e média do tamanho da área queimada por ocorrência em UCs brasileiras no período de 2008 a 2012.

Table 5. Distribution of the number of forest fires, burned area, and average size of the burned area per occurrence in Brazilian UCs from 2008 to 2012.

\begin{tabular}{lcccccc}
\hline \multirow{2}{*}{ Estados } & \multicolumn{2}{c}{ Ocorrências } & \multicolumn{2}{c}{ Área queimada } & Área queimada média & \multirow{2}{*}{$\begin{array}{c}\text { Classe de } \\
\text { tamanho }\end{array}$} \\
\cline { 2 - 5 } & $\mathbf{N}$ & $\mathbf{\%}$ & ha & \% & & II \\
RR & 1 & 0,13 & 4,00 & 0,001 & 4,00 & III \\
PA & 2 & 0,26 & 15,00 & 0,003 & 7,50 & III \\
AP & 2 & 0,26 & 62,60 & 0,013 & 31,30 & V \\
RO & 2 & 0,26 & $2.002,00$ & 0,425 & $1.001,00$ & V \\
TO & 19 & 2,47 & $302.548,03$ & 64,201 & $15.923,58$ & Classe V \\
\hline Região N & 26 & 3,39 & $304.631,63$ & 64,643 & $11.716,60$ & II \\
PE & 7 & 0,91 & 17,47 & 0,004 & 2,50 & III \\
AL & 9 & 1,17 & 35,40 & 0,008 & 3,93 & IV \\
PB & 66 & 8,59 & 333,46 & 0,071 & 5,05 & III \\
SE & 4 & 0,52 & 385,48 & 0,082 & 96,37 & V \\
CE & 158 & 20,57 & $2.593,84$ & 0,550 & 16,42 & 985,42 \\
MA & 3 & 0,39 & $2.956,26$ & 0,627 & &
\end{tabular}




\begin{tabular}{lcccccc} 
BA & 23 & 2,99 & $28.595,95$ & 6,068 & $1.243,30$ & V \\
PI & 69 & 8,98 & $59.355,93$ & 12,595 & 860,23 & V \\
\hline Região NE & 339 & 44,14 & $94.273,79$ & 20,005 & 278,09 & Classe V \\
\hline RS & 24 & 3,13 & $5.353,35$ & 1,136 & 223,06 & V \\
PR & 16 & 2,08 & $36.647,00$ & 7,776 & $2.290,44$ & V \\
\hline Região S & 40 & 5,21 & $42.000,35$ & 8,912 & $1.050,01$ & Classe V \\
\hline ES & 2 & 0,26 & 66,50 & 0,014 & 33,25 & III \\
RJ & 112 & 14,58 & $1.514,49$ & 0,321 & 13,52 & III \\
SP & 13 & 1,69 & $1.548,94$ & 0,329 & 119,15 & IV \\
MG & 89 & 11,59 & $17.177,95$ & 3,645 & 193,01 & IV \\
\hline Região SE & 216 & 28,13 & $20.307,88$ & 4,309 & 94,02 & Classe IV \\
\hline DF & 74 & 9,64 & 533,58 & 0,113 & 7,21 & III \\
MT & 69 & 8,98 & $4.452,20$ & 0,945 & 64,52 & IV \\
GO & 4 & 0,52 & $5.055,00$ & 1,073 & $1.263,75$ & V \\
\hline Região CO & 147 & 19,14 & $10.040,78$ & 2,131 & 68,30 & Classe IV \\
\hline Brasil & 768 & 100 & $471.254,43$ & 100 & 613,61 & Classe V \\
\hline
\end{tabular}

As médias das áreas queimadas, tempo para ataque e tempo para combate nas UCs dentro do período de estudo são observadas na Tabela 6.

Tabela 6. Médias das áreas queimadas (AQ) em hectares, tempo para o ataque (TA) em minutos e tempo de combate em minutos em UCs brasileiras no período de 2008 a 2012.

Table 6. Averages of burned areas (AQ) in hectares, time for attack (TA) in minutes, and combat time in minutes in Brazilian UCs from 2008 to 2012.

\begin{tabular}{lcccccc}
\hline Estados & AQ & Classe & TA & Classe & TC & Classe \\
\hline RR & 4,00 & II & 150,00 & IV & 90,00 & II \\
PA & 7,50 & III & 60,00 & II & $1.200,00$ & IV \\
AP & 31,30 & III & $11.925,00$ & V & $10.274,50$ & IV \\
RO & $1.001,00$ & V & $1.140,00$ & V & $6.060,00$ & IV \\
TO & $15.923,58$ & V & 515,47 & V & $3.914,26$ & V \\
\hline Região N & $11.716,60$ & V & $1.392,08$ & V & $4.212,69$ & IV \\
\hline PE & 2,50 & II & 50,00 & II & 97,86 & II \\
AL & 3,93 & II & 56,11 & II & 346,00 & III \\
PB & 5,05 & III & 43,24 & II & 552,27 & IV \\
SE & 96,37 & IV & 25,00 & I & 285,00 & III \\
CE & 16,42 & III & 59,04 & II & 582,43 & IV \\
MA & 985,42 & V & $1.800,00$ & V & $1.880,00$ & IV \\
BA & $1.243,30$ & V & 640,87 & V & $4.248,04$ & IV \\
PI & 860,23 & V & 177,93 & IV & $1.166,41$ & IV \\
\hline Região NE & 278,09 & IV & 134,38 & IV & 935,81 & IV \\
\hline RS & 223,06 & V & 34,08 & II & $1.079,08$ & IV \\
PR & $2.290,44$ & V & 540,63 & V & $3.190,56$ & IV \\
\hline Região S & $1.050,01$ & V & 236,70 & IV & $1.923,68$ & IV \\
\hline ES & 33,25 & III & 585,00 & V & $1.005,00$ & IV \\
RJ & 13,52 & III & 137,87 & IV & 835,27 & IV \\
SP & 119,15 & IV & 39,62 & II & $2.929,54$ & IV \\
MG & 193,01 & IV & 248,51 & IV & $1.143,37$ & IV \\
\hline Região SE & 94,02 & IV & 181,68 & IV & $1.089,83$ & IV \\
\hline DF & 7,21 & III & 43,85 & II & 105,19 & II \\
MT & 64,52 & IV & 162,43 & IV & 351,45 & III \\
GO & $1.263,75$ & V & $1.177,50$ & V & $1.612,50$ & IV \\
\hline Região CO & 68,30 & IV & 130,36 & IV & 261,80 & III \\
\hline Brasil & 613,61 & V & 194,82 & IV & 1012,51 & IV \\
\hline
\end{tabular}

FLORESTA, Curitiba, PR, v. 48, n. 1, p. 113-122, jan./mar. 2018.

Lima. G. S. et al.

ISSN eletrônico 1982-4688

DOI: $10.5380 /$ rf.v48 i1.53550 
A Tabela 7 apresenta as frequências e porcentagens de incêndios por classe de tempo para o ataque (da detecção até o primeiro ataque) nas UCs dentro do período analisado.

Tabela 7. Frequência e porcentagem dos incêndios florestais por classe de tempo para o ataque em UCs brasileiras no período de 2008 a 2012.

Table 7. Frequency and percentage of forest fires per time class for attack in Brazilian UCs from 2008 to 2012.

\begin{tabular}{ccc}
\hline Classe de duração (minutos) & Número & \% \\
\hline I (0 a 30) & 294 & 38,28 \\
II (31 a 60) & 196 & 25,52 \\
III (61 a 120) & 126 & 16,41 \\
IV (121 a 480) & 95 & 12,37 \\
V (acima de 480) & 57 & 7,42 \\
\hline
\end{tabular}

As frequências e porcentagens de incêndios por classe de tempo de combate (desde o primeiro ataque até a extinção) são observadas na Tabela 8.

Tabela 8. Frequência e porcentagem dos incêndios florestais por classe de tempo de combate em UCs brasileiras no período de 2008 a 2012.

Table 8. Frequency and percentage of forest fires per combat class in Brazilian UCs from 2008 to 2012.

\begin{tabular}{ccc}
\hline Classe de duração (minutos) & Número & \% \\
\hline I (0 a 60) & 188 & 24,48 \\
II (61 a 120) & 132 & 17,19 \\
III (121 a 480) & 222 & 28,90 \\
V (acima de 480) & 226 & 29,43 \\
\hline
\end{tabular}

A Tabela 9 traz as correlações entre o tamanho da área queimada, tempo para combate e número de combatentes envolvidos.

Tabela 9. Matriz de correlação de Spearman entre o tamanho da área queimada (AQ), tempo para o ataque (TA), tempo de combate (TC) e número de combatentes (NC) em UCs brasileiras no período de 2008 a 2012.

Table 9. Spearman correlation matrix among burned area (AQ), time to attack (TA), combat time (TC), and number of combatants (NC) in Brazilian UCs from 2008 to 2012.

\begin{tabular}{cccc}
\hline Parâmetros & AQ & TA & NC \\
\hline TA & 0,48 & 1 & 1 \\
NC & 0,54 & 0,32 & 0,58 \\
TC & 0,62 & 0,51 &
\end{tabular}

Por fim, na Tabela 10, são apresentadas as comparações entre as áreas queimadas e o número médio de incêndios por ano nos diferentes estados durante o período analisado.

Tabela 10. Comparação entre as áreas queimadas médias e número médio de ocorrências por ano nos diferentes estados brasileiros de 2008 a 2012, pelo teste de Scott-Knott ao nível 5\% de probabilidade.

Table 10. Comparison between average burned areas and average number of occurrences per year in Brazilian states from 2008 to 2012, by the Scott-Knott test at 5\% probability level.

\begin{tabular}{lccc}
\hline \multicolumn{2}{c}{ Área queimada média } & \multicolumn{2}{c}{ Número médio de ocorrências } \\
\hline \multicolumn{2}{c}{ Estado } & ha* $^{*}$ & \multicolumn{2}{c}{ Estado } & N.* \\
\hline TO & $60509,61 \mathrm{~A}$ & $\mathrm{CE}$ & $31,6 \mathrm{~A}$ \\
PI & $11871,19 \mathrm{~B}$ & $\mathrm{RJ}$ & $22,4 \mathrm{~A}$ \\
PR & $7329,40 \mathrm{~B}$ & $\mathrm{MG}$ & $17,8 \mathrm{~B}$ \\
BA & $5719,19 \mathrm{~B}$ & $\mathrm{DF}$ & $14,8 \mathrm{~B}$ \\
MG & $3435,59 \mathrm{~B}$ & $\mathrm{MT}$ & $13,8 \mathrm{~B}$ \\
RS & $1070,67 \mathrm{~B}$ & $\mathrm{PI}$ & $13,8 \mathrm{~B}$ \\
GO & $1011,00 \mathrm{~B}$ & $\mathrm{~PB}$ & $13,2 \mathrm{~B}$ \\
MT & $890,44 \mathrm{~B}$ & $\mathrm{RS}$ & $4,8 \mathrm{C}$ \\
MA & $591,25 \mathrm{~B}$ & $\mathrm{BA}$ & $4,6 \mathrm{C}$ \\
\hline
\end{tabular}




\begin{tabular}{llll}
\hline CE & $518,77 \mathrm{~B}$ & TO & $3,8 \mathrm{C}$ \\
RO & $400,40 \mathrm{~B}$ & $\mathrm{PR}$ & $3,2 \mathrm{C}$ \\
SP & $309,79 \mathrm{~B}$ & $\mathrm{SP}$ & $2,6 \mathrm{C}$ \\
RJ & $302,90 \mathrm{~B}$ & $\mathrm{AL}$ & $1,8 \mathrm{C}$ \\
DF & $106,72 \mathrm{~B}$ & $\mathrm{PE}$ & $1,4 \mathrm{C}$ \\
SE & $77,10 \mathrm{~B}$ & $\mathrm{GO}$ & $0,8 \mathrm{C}$ \\
PB & $66,69 \mathrm{~B}$ & $\mathrm{SE}$ & $0,8 \mathrm{C}$ \\
$\mathrm{ES}$ & $13,30 \mathrm{~B}$ & $\mathrm{MA}$ & $0,6 \mathrm{C}$ \\
AP & $12,52 \mathrm{~B}$ & $\mathrm{AP}$ & $0,4 \mathrm{C}$ \\
AL & $7,08 \mathrm{~B}$ & $\mathrm{ES}$ & $0,4 \mathrm{C}$ \\
PE & $3,49 \mathrm{~B}$ & $\mathrm{PA}$ & $0,4 \mathrm{C}$ \\
PA & $3,00 \mathrm{~B}$ & $\mathrm{RO}$ & $0,4 \mathrm{C}$ \\
RR & $0,80 \mathrm{~B}$ & $\mathrm{RR}$ & $0,2 \mathrm{C}$ \\
\hline
\end{tabular}

* médias seguidas das mesmas letras não diferem significativamente entre si.

\section{DISCUSSÃO}

Ao comparar as regiões brasileiras, percebeu-se que a maior eficiência por classe de tamanho de incêndio foi apresentada pelas regiões nordeste e centro-oeste, que tiveram 53,4 e 55,8\% dos incêndios nas classes I e II, respectivamente. A região sudeste apresentou $46,8 \%$ da área queimada nas classes iniciais. A região norte apresentou quase $70 \%$ dos incêndios na classe V, ou seja, grandes incêndios florestais que queimaram áreas maiores que 200 ha. Isso pode demonstrar que essa região apresenta uma baixa eficiência de combate, ou condições mais favoráveis à ocorrência de grandes incêndios florestais, como, por exemplo, dificuldade de acesso a locais atingidos.

Os resultados obtidos mostram um número maior de incêndios concentrado nas classes II, III e IV, o que demonstra baixa eficiência na supressão dos incêndios florestais. Analisando o período de 1994 a 1997, Soares e Santos (2002) observaram que quase $24 \%$ dos incêndios florestais estavam dentro da classe I. Esses resultados podem ser um indicativo de que houve um retrocesso na eficiência de combate a incêndios florestais no Brasil.

De acordo com os resultados, o estado do Ceará apresentou o maior número de ocorrências de incêndios florestais, seguido pelos estados do Rio de Janeiro, Minas Gerais e Distrito Federal. Os resultados diferem dos encontrados em estudos sobre o perfil dos incêndios florestais em áreas protegidas de 1994 a 2002 (SOARES; SANTOS, 2002; SANTOS et al., 2006). Nesses estudos, o estado de Minas Gerais foi apontado como o maior em número de ocorrências de incêndios, seguido pelo Espírito Santo, São Paulo e Bahia. É importante mencionar que o estudo feito pelos autores levou em conta, além dos registros das ocorrências de incêndios em unidades de conservação, os incêndios ocorridos em empreendimentos florestais.

A área queimada média, por incêndio, nas UCs do Brasil, foi de 613,61 ha. A região norte foi a que apresentou maior área queimada. Os grandes incêndios florestais, que ocorreram na região norte, foram responsáveis por $64,6 \%$ do total da área queimada em UCs no período analisado (Tabela 5). As unidades de conservação do estado de Tocantins tiveram uma área queimada de 302.548,03 ha, o que equivale a 64,2\% do total de área queimada para o Brasil no período analisado. Ressalta-se que os incêndios ocorridos no ano de 2010 na Estação Ecológica da Serra Geral do Tocantins queimaram 271.251,09 ha. Em segundo lugar, apareceu a região nordeste, seguida pela sul, sudeste e, por fim, a centro-oeste.

Os resultados mostraram que, seguido do estado de Tocantins, o estado do Piauí apresentou a maior área queimada em UCs. Os outros estados com maiores áreas atingidas foram Paraná, Bahia e Minas Gerais. Pode-se observar que uma maior área queimada não estava, necessariamente, relacionada a um maior número de ocorrências de incêndios florestais. Os trabalhos realizados por Santos et al. (2006) e Soares e Santos (2002) apontaram Minas Gerais como o estado com maior área queimada no período, seguido por São Paulo, Bahia e Espírito Santo.

No estudo realizado por Lima e Soares (1992), o qual levou em consideração os incêndios em empresas e instituições florestais, a área queimada média, por incêndio, foi de 66,7 ha no período de 1984 a 1987. Este valor passou para cerca de 135 ha nos anos de 1994 a 1997 (SOARES; SANTOS, 2002). O grande aumento em área queimada por incêndio pode ser resultado do aumento do número de grandes incêndios florestais, que destroem áreas imensas e impossibilitam uma rápida ação de controle. Também, podem ser citados os períodos de estiagem prolongada, temperaturas elevadas e ventos intensos como elementos meteorológicos responsáveis pelo aumento dos grandes incêndios florestais.

Nos países alpinos, o tamanho médio dos incêndios florestais foi muito diferente. De acordo com Wastl et al. (2013), no período de 1951 a 2010, o tamanho médio dos incêndios florestais alpinos foi entre 5,6 ha no inverno e 6,4 ha no verão. O maior tamanho médio de incêndio ocorrido na França durante o verão ( $>8$ ha) ocorreu, provavelmente,

FLORESTA, Curitiba, PR, v. 48, n. 1, p. 113-122, jan./mar. 2018.

Lima. G. S. et al.

ISSN eletrônico 1982-4688

DOI: $10.5380 /$ rf.v48 i1.53550 
devido às características mediterrânicas da área, enquanto que, na Alemanha e na Áustria, o tamanho médio fogo não excedeu 1,4 ha em ambas as estações. Grandes incêndios individuais ocorreram principalmente em conexão com longos períodos de seca e em regiões de difícil acesso, onde as operações de combate são difíceis. O maior incêndio individual (11.580 ha) foi registrado na parte mediterrânica da França. Na China, o tamanho da maioria dos incêndios florestais é menor que 100 ha e apenas $0,21 \%$ são maiores do que 100 ha (TIAN et al., 2013).

Em termos de tempo para o ataque, a detecção e supressão precoce de incêndios florestais são os principais caminhos para minimizar seus danos. A questão crítica em sistemas de monitoramento de incêndios florestais é a resposta imediata a fim de minimizar a escala da destruição (BAO et al., 2015). Neste estudo, observou-se um tempo médio para o ataque de 194,82 minutos (classe IV) para uma área queimada média de 613,61 ha em UCs no Brasil (Tabela 6). Lima e Soares (1992) encontram um valor médio de tempo para ataque de cerca de 73 minutos (classe III). Segundo os autores, o longo tempo para o ataque pode ocorrer devido à necessidade de se percorrerem grandes distâncias até o local do fogo, a um sistema de mobilização pouco eficiente ou ao difícil acesso aos locais do fogo. A descentralização da equipe de combate pode ser uma das medidas para se reduzir o tempo para ataque ao fogo, uma vez que pode se reduzir a distância a ser percorrida para se iniciar o combate. Em simulações realizadas na Austrália por Penman et al. (2013), o aumento do esforço de supressão e diminuição do tempo de resposta resultaram em uma diminuição no tamanho médio da área queimada, com diferenças significativas entre todas as comparações (incluindo variações nas condições meteorológicas e controle da quantidade de combustível disponível).

O estado de Sergipe apresentou o menor tempo médio para ataque dentre os estados brasileiros, seguido pelo Rio Grande do Sul, São Paulo, Paraíba e Distrito Federal. Amapá, Maranhão, Goiás e Rondônia foram os estados com maior tempo médio de mobilização, podendo ser considerados como pontos discrepantes e como os principais responsáveis pela média elevada do tempo para ataque no Brasil.

Em cerca de $38 \%$ dos incêndios, foi possível chegar ao local do fogo em até 30 minutos (classe I) e, em quase $64 \%$ dos incêndios, esse tempo foi de até 60 minutos (classes I e II) (Tabela 7). Cerca de 20\% dos incêndios registrados tiveram o tempo para o ataque maior que 2 horas (classes IV e V). De acordo os resultados encontrados por Lima e Soares (1992) para os incêndios florestais no período de 1984 a 1987, em 48\% dos casos, conseguiu-se chegar ao incêndio em até 30 minutos (classe I) e, em torno de $70 \%$ das vezes, em até 60 minutos (classes I e II). Segundo eles, o número de casos que levaram mais de 2 horas (classes IV e V) para se iniciar o ataque foi de $11 \%$.

Em termos de tempo de combate, pode-se observar que a média do Brasil foi de 1.012,51 minutos (Tabela 6). O estado do Amapá apresentou o maior tempo de combate dentre todos (10.274,50 minutos), assim como o maior tempo para o ataque, com um valor muito superior à média nacional. Esse resultado elevado é um indicativo de baixa eficiência de combate no estado e pode estar relacionado às condições metereológicas, material combustível e topografia, ou seja, às dificuldades de se controlar o fogo (LIMA; SOARES, 1992).

Os estados de Rondônia, Bahia, Tocantins, Paraná, São Paulo, Maranhão, Goiás, Pará, Piauí, Minas Gerais e Rio Grande do Sul também tiveram médias de tempo de combate maiores do que as médias do país, estando incluídos na classe IV. Em contrapartida, os estados de Roraima, Pernambuco e Distrito Federal (todos dentro da classe II) apresentaram uma melhor eficiência em termos de tempo de combate.

Pela Tabela 8, pode-se perceber que cerca de 42\% dos incêndios em UCs no período de 2008 a 2012 tiveram uma média de tempo de combate de até 120 minutos (classes I e II). De acordo com Lima e Soares (1992), os incêndios ocorridos no período de 1984 a 1987 apresentaram um tempo de combate médio de até 120 minutos em $48 \%$ das ocorrências. Esses resultados sugerem uma baixa eficiência de controle aos incêndios florestais em UCs no que se refere ao tempo de combate. Cerca de 58\% dos incêndios estavam inclusos dentro das classes III e IV, ou seja, apresentam tempo médio de combate maior que 120 minutos, o que pode significar que o sistema de combate a incêndios florestais no Brasil ainda é pouco eficiente, seja por falta de pessoas preparadas ou de equipamentos adequados para o combate.

De acordo com os dados da Tabela 9, existe uma correlação significativa, mostrando que quanto maior o tempo para o ataque, maior o tamanho da área queimada e maior o tempo de combate, o que evidencia a importância desse componente. Um maior número de combatentes, por sua vez, não significa menor área queimada nem menor tempo de combate. Também, foi constatado que quanto maior o tempo de combate, maior a área queimada.

Segundo alguns estudos que se propuseram a realizar entrevistas com os brigadistas das UCs, verificouse que, de forma geral, há uma elevada carência de máquinas, torres de observação, locais de captação de água e equipamentos de proteção pessoal (EPI). As maiores dificuldades de trabalho salientadas foram a carência de infraestrutura, o patrulhamento insuficiente, ausência de apoio das populações circunvizinhas e os frequentes atrasos no início das atividades de prevenção. O investimento realizado nos últimos anos na contratação de brigadistas e aquisição de material de combate aparentemente não foi suficiente para a redução das áreas queimadas. Ainda existem diversos problemas organizacionais e uma grande carência de equipamentos, pessoal e investimento em atividades preventivas (PEREIRA et al., 2004; FIEDLER et al., 2006; TEBALDI et al., 2013). 
Os resultados apontam, também, para uma falta de correlação entre o número de ocorrências e o tamanho da área queimada, evidenciando a diversidade encontrada no território nacional e reforçando a relevância do nível local para o sucesso ou fracasso de determinadas políticas. Isso implica que os princípios e as medidas adotadas terão de ser adaptadas às possibilidades reais e específicas de intervenção que derivam do contexto territorial particular (GALIANA et al., 2013).

Um dos problemas encontrados na execução do estudo foi a quantidade de relatórios incompletos que ainda chega ao Prevfogo. Apenas $41 \%$ dos ROIs apresentavam informações básicas, como o tamanho da área queimada, tempo para o ataque e tempo de combate. Segundo Bontempo et al. (2011), uma possível explicação para isso são as circunstâncias que envolvem um combate a incêndio florestal, as quais são de caráter de urgência e de grande desgaste físico e emocional, o que contribui para que o preenchimento seja colocado em segundo plano e, muitas vezes, deixado de lado. Quando se retoma o preenchimento do formulário, muitas informações já se perderam ou foram esquecidas, gerando relatórios incompletos, como já detectados pelos órgãos competentes. Assim, é preciso haver investimento na contratação e capacitação de recursos humanos, bem como na aquisição de equipamentos e instrumentos adequados, o que permitirá a obtenção de dados confiáveis.

\section{CONCLUSÕES}

Por meio do estudo de 768 registros da ocorrência de incêndios no período de 2008 a 2012, pode-se concluir, a respeito da eficiência de combate aos incêndios florestais em unidades de conservação no Brasil, que:

- Comparado com dados anteriores, o Brasil ainda apresenta uma baixa eficiência de combate a incêndios florestais.

- A região norte, apesar de apresentar os menores números de ocorrências, apresentou maior área queimada, significando menor eficiência no combate.

- A área queimada média, por incêndios florestais, nas unidades de conservação, foi de 613,61 ha (classe V), o que representa uma baixa eficiência de combate.

- Quase $51 \%$ dos incêndios florestais em unidades de conservação queimaram uma área maior que 4,0 ha, o que indica piora na eficiência no combate no Brasil em relação a estudos anteriores.

- O tempo médio para ataque (tempo de mobilização) das equipes de combate foi de 194,82 minutos (classe IV). Apesar disso, cerca de 63,80\% dos incêndios registrados nas UCs do Brasil estão nas classes I e II de tempo para ataque, demonstrando que a dificuldade de acesso ou grandes distâncias podem ser os responsáveis.

- O Brasil apresentou um tempo médio de combate a incêndios florestais em unidades de conservação de 1.012,51 minutos (classe IV). Contudo, cerca de 42\% das ocorrências de incêndios nas UCs do Brasil estão nas classes I e II de tempo de combate, o que indica baixa eficiência nesse parâmetro.

- O preenchimento correto dos ROIs permitiria a realização de um melhor diagnóstico para a remediação do problema.

\section{REFERENCIAS}

ADÁMEK, M.; BOBEK, P.; HADINCOVÁ, V.; WILD, J.; KOPECKÝ, M. Forest fires within a temperate landscape: a decadal and millennial perspective from a sandstone region in central Europe. Forest Ecology and Management, v. 336, p. 81 - 90, 2015.

BAO, S.; XIAO, N.; LAI, Z.; ZHANG, H.; KIM, C. Optimizing watchtower locations for forest fire monitoring using location models. Fire Safety Journal, v.71, p.100 - 109, 2015.

BONAZOUNTAS, M.; KALLIDROMITOU, D.; KASSOMENOS, P.; PASSAS, N. A decision support system for managing forest fire casualties. Journal of Environmental Management, v. 84, n. 4, p. 412 - $418,2007$.

BONTEMPO, G. C.; LIMA, G. S.; RIBEIRO, G. A.; DOULA, S. M.; SILVA, E. Registro de Ocorrência de Incêndio (ROI): evolução, desafios e recomendações. Biodiversidade Brasileira, v. 1, n. 2, p. 247 - $263,2011$.

FIEDLER, N. C.; RODRIGUES, T. O.; MEDEIROS, M. B. de. Avaliação das condições de trabalho, treinamento, saúde e segurança de brigadistas de combate a incêndios florestais em unidades de conservação do Distrito Federal: estudo de caso. Revista Árvore, v. 30, n. 1, p. 55 - 63, 2006.

GALIANA, L.; AGUILAR, S.; LÁZARO, A. An assessment of the effects of forest-related policies upon wildland fires in the European Union. Applying the subsidiarity principle. Forest Policy and Economics, v. 29, p. 36-44, 2013.

GOBBO, S. D. A.; GARCIA, R. F.; EUGENIO, F. C. Prevenção e combate às queimadas: trabalho e percepção da brigada de incêndio do Parque Nacional do Caparaó. Engenharia Ambiental, v. 10, n. 3, p. 145-159, 2013.

FLORESTA, Curitiba, PR, v. 48, n. 1, p. 113-122, jan./mar. 2018.

Lima. G. S. et al.

ISSN eletrônico 1982-4688

DOI: $10.5380 /$ rf.v48 i1.53550 
GOUVEIA, G. P.; MORAIS, J. C. M. de. Operações de prevenção e combate aos incêndios florestais no estado de Roraima - 2003/2004. Floresta, v. 34, n. 2, p. 199-204, 2004.

IBAMA (INSTITUTO BRASILEIRO DO MEIO AMBIENTE E DOS RECURSOS NATURAIS RENOVÁVEIS). Sistema Nacional de Informações Sobre Fogo - SISFOGO. Disponível em: <http://siscom.ibama.gov.br/sisfogo/>. Acesso em: 18/06/2015.

LIMA, G. S.; SOARES, R. V. Avaliação de eficiência de combate aos incêndios florestais no Brasil. Floresta, v. 22, n. 1/2, p. 25-38, 1992.

MAGALHÃES, S. R. de; LIMA, G. S.; RIBEIRO, G. A. Avaliação do combate aos incêndios florestais no Parque Nacional da Serra da Canastra. Floresta e Ambiente, v. 18, n. 1, p. 80-86, 2011.

MAVSAR, R.; CABÁN, A. G.; FARRERAS, V. The importance of economics in fire management programmes analysis. Towards Integrated Fire Management - outcomes of the European Project Fire Paradox 2010, $230 \mathrm{p}$.

MMA (MINISTÉRIO DO MEIO AMBIENTE). Dados consolidados das unidades de conservação. 2016. Disponível em: <http://www.mma.gov.br/areas-protegidas/cadastro-nacional-de-ucs/dados-consolidados>. Acesso em: 03/05/2016.

PACHECO, A. P.; ClARO, J.; FERNANDES, P. M.; NEUFVILlE, R.; OLIVEIRA, T. M.; BORGES, J. G.; RODRIGUES, J. C. Cohesive fire management within an uncertain environment: a review of risk handling and decision support systems. Forest Ecology and Management, v. 347, p. 1-17, 2015.

PENMAN, T. D.; COLLINS, L.; PRICE, O. F.; et al. Examining the relative effects of fire weather, suppression and fuel treatment on fire behaviour - a simulation study. Journal of Environmental Management, v. 131, p. 325-333, 2013.

PEREIRA, C. A.; FIEDLER, N. C.; MEDEIROS, M. B. de. Análise de ações de prevenção e combate aos incêndios florestais em unidades de conservação do Cerrado. Floresta, v. 34, n. 2, p. 95-100, 2004.

SAN-MIGUEL-AYANZ, J.; SCHULTE, E.; SCHMUCK, G.; CAMIA, A. The European Forest Fire Information System in the context of environmental policies of the European Union. Forest Policy and Economics, v. 29, p. 19-25, 2013.

SANTOS, J. F.; SOARES, R. V.; BATISTA, A. C. Perfil dos incêndios florestais no Brasil em áreas protegidas no período de 1998 a 2002. Floresta, v. 36, n.1, p. 93-100, 2006.

SOARES, R. V.; SANTOS, J. F. Perfil dos incêndios florestais no Brasil de 1994 a 1997. Floresta, v. 32, n. 2, p. 219-232, 2002.

TEBALDI, A. L. C.; FIEDLER, N. C.; JUVANHOL, R. S.; DIAS, H. M. Ações de prevenção e combate aos incêndios florestais nas unidades de conservação estaduais do Espírito Santo. Floresta e Ambiente, v. 20, n. 4, p. 538-549, 2013.

TETTO, A. F.; SOARES, R. V.; BATISTA, A. C.; WENDLING, W. T. Eficiência do combate aos incêndios florestais, no período de 1965 a 2009, na Fazenda Monte Alegre, Paraná. Scientia Forestalis, v. 40, n. 96 , p. 483 $-489,2012$.

TIAN, X.; ZHAO, F.; SHU, L.; WANG, M. Distribution characteristics and the influence factors of forest fires in China. Forest Ecology and Management, v. 310, p. 460-467, 2013.

WASTL, C.; SCHUNK, C.; LÜPKE, M.; et al. Large-scale weather types, forest fire danger, and wildfire occurrence in the Alps. Agricultural and Forest Meteorology, v. 168, p. 15-25, 2013.

ZAITSEV, A. S.; GONGALSKY, K. B.; MALMSTRÖM, A.; PERSSON, T.; BENGTSSON, J. Why are forest fires generally neglected in soil fauna research? A mini-review. Applied Soil Ecology, v. 98, p. 261-271, 2016. 